\section{Tectonics as theory, tectonics as history}

\section{B.C. Burchfiel}

Geology of the Continental Margins. By G. Boillot. Pp.115. ISBN 0-582-30036-3. (Longman: 1981.) £4.95, \$11.95. Geotectonics. By V.V. Beloussov. Pp.330. ISBN 0-387-09173-4. (Springer-Verlag: 1980.) DM48, \$28.40. Tectonics and Landforms. By Cliff Ollier. Pp.324. Hbk ISBN 0-582-30032-0; pbk ISBN 0-58230033-9. (Longman: 1981.) Hbk £20, \$55; pbk $£ 9.95, \$ 24$.

WITH our rapidly increasing understanding of global tectonics, books published on the subject are commonly outdated within a few years of publication. Two of the books reviewed here (Geology of Continental Margins and Geotectonics) are translations of previously published works, which originally appeared several years ago and

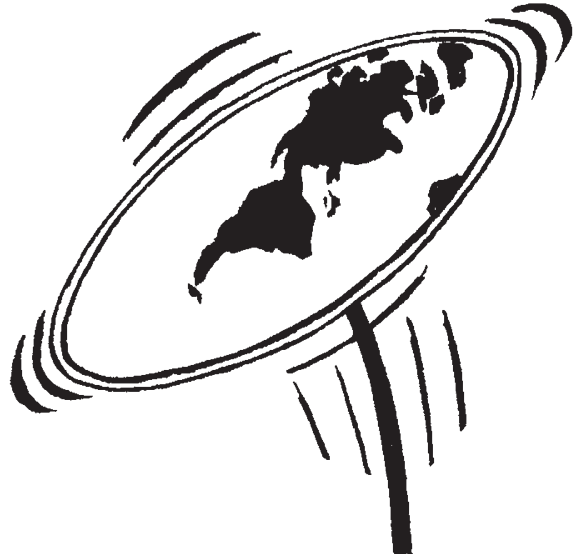

contain material which is already somewhat out of date. Tectonics and Landforms, in contrast, promises an interesting approach and in some instances makes excellent use of recent tectonic concepts and their relationship to geomorphology. However, books on such broad topics often cannot adequately cover each subject within their scope, and this one is no exception.

Geology of Continental Margins is a translation of a book first published in French in 1978. No subject in the earth sciences has evolved more rapidly in the past five years, which renders the book introductory at best and outdated at worst. While some of the material presented is still generally valid, recently developed details of continental margin evolution, particularly passive margin evolution, are obviously missing.

Instead of focusing on the great wealth of information which now exists about the geology of the continental margins of the world, the book concentrates on plate tectonic models of continental margins and presents little real data; if readers are looking for factual information on particular continental margins, they won't find it in this book. I was also surprised to find lengthy discussions of subduction, the deep seismic structure of subduction zones, paired metamorphic belts, geosynclines and collisional tectonics.

Although advertisements for the book suggest that some updating has been done for the English edition, it seems to have been minor. Some articles published in 1979 have been added to the "further reading" section, but little new data appears in the written part of the text. In my view this is a model-orientated, highly simplified presentation of continenta margins. The emphasis is on the plate tectonic development of continental margins, rather than on what they are really like.

Geotectonics is a slightly-updated translation of a book published in Russian in 1976. Some of the data presented were published as recently as 1978 . Even so, the book presents a view of the geotectonics of the Earth in the well-known and unique conceptual framework developed by Beloussov himself. In the preface it is suggested that the reader should be familiar with the principles of tectonophysics developed in Beloussov's Structural Geology (published in 1978, in French). 1 think this would be advisable, as much of the terminology and some of the conceptual ideas in this work need such a background.

Most of the geological examples and figures presented are either from older works - 1960s or earlier - or are Beloussov's reinterpretations of work by other scientists. The examples cited, as well as those not presented for the same area, were apparently selected to develop the author's particular view of geotectonics. Vertical movement of material in the crust, mantle and core remain the dominant principle of Beloussov's view of the evolution of the Earth; horizontal movements of rocks are considered to be of limited importance. Basification of continental crust leads to the formation of ocean crust. These and other concepts developed by the author are generally not acceptable to many of us, but deserve publication. If we cannot explain more adequately the geotectonic evolution of the Earth, and do not continue to test all reasonable hypotheses, earth science will stagnate.

Except for a five-page discussion of plate tectonics near the end of the book and another seven pages of critique, the book is all Beloussovian tectonics and will be of interest to only avid scientists interested in the subject.

The purpose of Tectonics and Landforms is to relate tectonics and structure to landforms on a scale which ranges from continents and oceans to local surficial features. This is truly an admirable purpose and potentially very exciting and interesting. With such a broad purpose but abbreviated length, the presentation has some successes, but inevitably some subjects are treated superficially. Much of Ollier's presentation focuses on large-scale tectonics, developing the concepts of plate tectonics and its resultant geomorphic features. From this basis, a great variety of subjects, such as flow of ice and rock, planation surfaces and drainage patterns are covered in very short sections. Not only are modern concepts developed in the book, but reviews of older, historical, and in many cases obsolete, theories are also presented.

I was particularly pleased to see that many of the pioneering ideas on tectonics by S.W. Carey are discussed, but I doubt whether a chapter on the expanding Earth was necessary, particularly when most of the book is devoted to the development of plate tectonics. In several places the author gives plate tectonic explanations for various features followed by a disclaimer that other explanations which are incompatible with plate tectonics, such as interpretations based on expanding Earth models, should not be discounted.

Tectonics and Landforms is well written, well organized and well illustrated. Although the author claims to aim at senior undergraduates, in my opinion the book is too superficial for students at that level. Rather, it would be better suited to an introductory audience, but even then offers a rather uneven overview of a great variety of earth science subjects.

B.C. Burchfiel is a Professor in the Department of Earth and Planetary Sciences at the Massachusetts Institute of Technology.

\section{Crystal growth}

\section{R.A. Howie}

Crystallography: An Introduction for Earth Science (and Other Solid State) Students. By E.J.W. Whittaker. Pp.254. Hbk ISBN 0-08-023805-X; pbk ISBN 0-08-023804-1. (Pergamon: 1981.) Hbk $£ 13.50, \$ 32.50$; pbk £8.35, \$19.95. Mineralogy for Students, 2nd Edn. By M.H. Battey. Pp.355. ISBN 0-582-44005X. (Longman: 1981.) £8.95, \$19.95.

Crystallography is presented in two evenlydivided parts: the first deals with morphological crystallography, symmetry and systems, stereographic projections, and derivation of symmetry and forms in all 32 crystal classes, while Part II covers the fundamental features of X-ray crystallography, the 14 Bravais lattices, the interpretation of powder photographs, $\mathrm{X}$-ray diffraction by single crystals and symmetry in repeating patterns. Part I thus somewhat overlaps in coverage with $A n$ Introduction to Crystallography (4th Edn, Longman; 1971) by F.C. Phillips and A.C. Bishop's An Outline of Crystal Morphology (Hutchinson, 1967) though, 